\title{
Mobile robots and evolutionary optimization algorithms for green supply chain management in a used-car resale company
}

\author{
V. Sathiya ${ }^{1} \cdot$ M. Chinnadurai ${ }^{2} \cdot$ S. Ramabalan ${ }^{3} \cdot$ Andrea Appolloni $^{4}$
}

Received: 31 March 2020 / Accepted: 25 September 2020

(c) Springer Nature B.V. 2020

\begin{abstract}
To ensure environment friendly products in the international supply chain scenario, an important initiative is reverse supply chain (RSC). The benefits (environmental and financial) from a RSC are influenced by disposal of reusable parts, cost factors and emissions during transportation, collection, recovery facilities, recycling, disassembly and remanufacturing. During designing a network for reverse supply chain, some objectives related to social, economic and ecological concerns are to be considered. This paper suggests two strategies for reducing the costs and emissions in a network of RSC. This research work considers design of RSC for a used-car resale company. First strategy outlines the design of a mobile robot-solar-powered automated guided vehicle (AGV) for reducing logistic cost and greenhouse gas (GHG) emissions. The second strategy proposes a new multi-objective optimization model to reduce the costs and emissions of GHG. Strict carbon caps constraint is used as a guideline for reducing emissions. The proposed strategies are tested for a real-world problem at Maruti True Value network design in Tamil Nadu and Puducherry region of India. Two algorithms namely Elitist Nondominated Sorting Genetic Algorithm (NSGA-II) and Heterogeneous Multi-Objective Differential Evolution algorithm (HMODE) are proposed. HMODE is a new improved multi-objective optimization algorithm. To select the best optimal solution from the Pareto-optimal front, normalized weighted objective functions (NWOF) method is used. The strength or weakness of a Pareto-optimal front is evaluated by the metrics namely ratio of non-dominated individuals (RNI) and solution spread measure (SSM). Also, Algorithm Effort (AE) and Optimiser Overhead (OO) are utilized to find the computational effort of multi-objective optimization algorithms. Results proved that proposed strategies are worth enough to reduce the GHG emissions and costs.
\end{abstract}

Keywords Green supply chain management - Reverse supply chain - Low carbon logistics · Greenhouse gas (GHG) emissions · Robot · Automated guided vehicle (AGV) · Multiobjective optimization $\cdot$ NSGA-II $\cdot$ HMODE

V. Sathiya

sathiyav2105@gmail.com

Extended author information available on the last page of the article 


\section{Introduction}

The customer awareness regarding eco-friendly products is on the rise. This forces the original products manufacturers responsible for end-of-life products (Devika Kannan et al. 2012). Simultaneously, the number of products disposed by the consumers is also growing. The increasing energy prices, climate change, limited resources, increasing emissions, increasing population, disposal capacities and enhanced standard of life urge the research and industry people to design and develop more strategies on sustainable supply chain taking into account industry social responsibilities. The concept of introducing sustainability in supply chain is a new trend. Also, its implementation is ever-increasing.

The current scenario is that a reverse flow of products from customers to industries is also happening. It is occurring in the sectors like electronic products, beverages, pharmaceuticals and automobiles. More changes are happening in supply chain and reverse supply chain of the automobile sector. So, more strategies are adopted by the industries to increase the life of the vehicles by doing repair and remanufacturing. The infrastructure facilities of automobile industries are very much improved.

When compared to forward supply chain (FSC), reverse supply chain (RSC) is less investigated for automobile sector. The main concepts of FSC namely coordination, bullwhip effect and postponement can be used for design of RSC with suitable modifications (Joseph D Blackburn et al. 2004). An efficient RSC strategy is needed for highdemand uncertainty goods like used-cars. A best characteristic of a SC is marginal value of time (MVT). Responsive RSC has to be designed for high MVT products. But, efficient RSC design is suitable for low MVT products. In both cases, managers of industries generally focus on local efficiencies by giving low-cost solutions. They are bringing the used products to a nearby central facility for doing repair and maintenance activities. This is due to the fact that transportation delay plays a vital role in this activity. So, to reduce transportation time, a best strategy is desired. Products returns through RSC are for creating a value stream and not for reducing financial loss. So, for a good company, RSC should be given proper attention as in the case of FSC. A good RSC strategy will boost value of a company. For designing a good RSC for a used product, five key activities are involved. They are product collection, reverse logistics, inspection, repair activities and sending or selling the product to customer. Product collection is the activity of getting used products from users. Reverse logistics is for sending the products from collection centers to minor and major repair centers. The condition of product and disposing time is most profitable in making decision of reuse.

A lot of literature reviewed the different sides of sustainability in supply chain like energy use, green network design (Cynthia Waltho et al. 2019), diminishing of GHG emissions (Jaegler and Gondran 2014), production planning, remanufacturing control, product recovery, inventory management, waste management and reverse logistics (Susana Garrido Azevedo et al. 2017, Chaher Alzaman 2016, Nageswara Reddya et al. 2020, Alkhayyal 2019a, Bandar Alkhayyal. 2019a, b). Ilgin and Gupta (2010) discussed environment friendly production and product recovery. The cited literature addressed the common issues in environment friendly manufacturing, environment friendly design, recycling, remanufacturing, inventory control and production planning and a recovery process of products in eco-favorable manufacturing view. 


\section{Literature review}

A vital goal of supply chain is reducing emissions. Now, the trade-offs in supply chain are cost (Chaudhary and Vrat 2020), quality, service and carbon. Earlier trade-offs are about service, cost and quality. Paksoy et al. (2011) considered a bounded supply chain in view of logistics price function and transportation GHG emissions. They checked the correlation between the environmental and operative performance measures.

Abdallah et al. (2012) addressed carbon emissions in supply chain and supplier selection by life-cycle assessment approach. Diabat and Simichi-Levi (2010) modeled a mixedinteger optimization model to get the best strategy for minimizing the cost and to meet the carbon cap. Chaabane et al. (2012) tested the impression of carbon emissions in design of a good CLSC network by using LCA principles. They considered an aluminum industry to check the bond between environmental and economic dimensions by considering various strategies. Diabat et al. (2013a, b) discussed the issues related to facility location issue and cost in CLSC by considering carbon emissions and procurement costs. Fahimnia et al. (2013) checked the influences on carbon footprint in reverse and forward supply chain by a MILP model. They used dollar carbon cost for estimating carbon emissions. Benjaafar et al. (2013) tested more number of lot sizing models to explain the impacts of carbon emissions in operations decisions. Also, they discussed the method for emissions reduction without much increase in costs by doing only operational adjustments. Jin et al. (2014) examined various carbon polices influence on supply chain and selection of transportation mode for a big retailer.

The first strategy proposed in this research to diminish GHG emissions in the RSC is usage of mobile robots (AGV). Due to proliferation of markets, environmental awareness, polices of government and sustainability, supply chain (SC) actions are to be done by automated and flexible systems. So AGVs are used in the manufacturing systems to get benefits from environmental and social sustainability and economic dimensions. AGVs give diminished energy consumption, increased productivity, savings in labor cost, enhanced safety and emissions (Dimitrios Bechtsis et al. (2017a)). AGVs need some fixed capital investments. But they give more economic benefits than conventional vehicles, as they require minimum maintenance cost and human interventions. They serve for $24 / 7$ basis which leads to reduce labor cost (Kumar and Rahman 2014). They reduce accidents on pedestrian workers and vehicle drivers. Further they increase productivity in all logistics operations and give service to all levels in SC.

Kalakou et al. (2015) proved that in airport drop-off locations, AGVs decrease delivery time of passengers' bags to 20-30 min. Gelareh et al. (2013) proved that in some container terminals, they improve the cranes service time up to 23\%. Peterson and Michalek (2013) expressed that Electric powered AGVs reduce energy consumption in SC operations. Schmidt et al. (2015) pointed that AGVs reduce GHG emissions like $\mathrm{NO}_{2}$ and $\mathrm{CO}_{2}$. Choe et al. (2016) proved that AGVs reduce empty travel distances. Bostelman et al. (2014) discussed that AGVs improve human safety which gives social impact. Manual forklifts operations in logistics are major and frequent reasons of accidents. During 1998-2007, more than three million accidents happened in warehouse and transport activities of European Union (Sabattini et al. 2013). The errors done by forklift operators and some blind spots existing in manufacturing operations are the main sources for the accidents. Shukla and Karki (2016) quoted that AGVs are best to create an ergonomic workplaces in which workers will interact and cooperate with machines, to create skilled jobs and to use in hazardous environments. 
In 2014, for logistics, the world AGV systems' usages were 2564 which is $29 \%$ higher than that of 2013. During 2015-2023, 13,300 AGV systems will be used. It is the prediction of World Robotics in 2015. Fazlollahtabar et al. (2015) pointed that particularly AGVs give automated loading, unloading and transportation capabilities. So they have applications in container terminals, warehouses, manufacturing plants, service industries and material handling operations. In 2012, Amazon bought Kiva Systems which makes warehouse robot. Amazon deployed 15,000 AGVs in ten important warehouses to get reduced lead time and to increase levels of customer service (D'Andrea 2012). A survey report of Material Handling Industry taken among 900 professionals (Industry and (MHI) Annual Industry Report 2016) indicates the following: (i) 51\% professionals predict a major contribution by AGVs will be in SCs. (ii) $33 \%$ professionals say major investments will be in AGVs in next few years. The Pan-Robots project of EU seventh framework program develops public interest on development initiatives, supporting research and promoting innovations in AGVs (Sabattini et al. 2013). The aim of the project is to develop few highly automated systems in logistics to get cost reduction, manufacturing flexibility, energy efficiency and also accidents-free operations. AGVs improve sustainability in SCs to get benefits in operational, tactical and strategic levels. Giret et al. (2015) pointed that AGVs give a scope for further investigation in SC. Bechtsis et al. (2017a) and Guilherme T Aguiara et al. (2019) detailed more applications of AGVs in SC. Further the research and developing systems related to AGVs deployment in SCs are not fully addressed. There is a tremendous scope for further investigation.

In this research, second strategy proposes a new multi-objective optimization model of reverse supply chain with full valuation of emissions is considered to determine the optimal number of cars to be collected by all collection centers that will diminish the total cost and GHG emissions. The proposed model considers Maruti True Value network design. All used cars of Maruti Suzuki Company have been bought, repaired and resold by Maruti True Value Company. The data used in this research work are actual site locations of Maruti True Value collection, repair and resale centers in Tamil Nadu and Puducherry region.

\subsection{Review background result}

From the literature review, it is concluded that (1) there is less literature found to reduce cost and GHG emissions in RSC for used cars. (2) An optimization method is needed for reducing reverse logistics cost and emissions in Maruti True Value. (3) AGVs are used only in Industries and car parking areas. So, there is a great scope for AGV's usage in used cars' transportation. (4) Solar powered AGV can be used for reducing costs and emissions of a RSC. To overcome these limitations, this research work proposes a new multi-objective optimization method and a new design of solar powered AGV for transportation of used cars in a RSC network.

The paper is structured in the following fashion. In Sect. 3, proposed strategies are elaborated. Application of proposed model is discussed in Sect. 4. In Sect. 5, the proposed optimization methodologies those have been used in this research study are briefed. In Sect. 6, results got from various techniques and their discussions are given. The conclusions and future recommendations are presented in Sect. 7. Managerial implication is discussed in Sect. 8. 


\section{Proposed strategies}

\subsection{Strategy 1: an insight about a solar powered car carrier AGV design}

Three processes are involved in loading and unloading operations of cars in an RSC. They are (a) collection of used cars from customers in collection centers, (b) transportation of cars to major workshops from collection centers and (c) transportation of cars to major resale centers from major workshops.

This paper gives an insight into developing a solar powered AGV for RSC in an automobile sector. To improve performance and to reduce costs and emissions of RSC, AGVs are used. AGV overall design specifications are: (a) Ability to find the shortest route to reach the destination from the initial point to do works with help of supervisory control computer. (b) Capability to transport all varieties of cars. Each car has a standard weight and dimensions. (c) Capability to find and map the locations without getting any guidance of magnetic tapes, electric wires and magnetic tapes. Rely on other devices reduces flexibility. (d) Obstacle avoidance to avoid collisions with the obstacles. (e) Ability to set transportation priorities to transport cars in terms of avoiding dynamic obstacles. (f) Providing a very good interaction between AGVs team and supervisor computer.

\subsubsection{Specifications of AGV}

Figure 1 shows a model of AGV system used in car transportation applications. A few technical specifications of AGV are: Load Weights-Max weight of a single car is $2000 \mathrm{~kg}$. Max Weight of an AGV is $5000 \mathrm{~kg}$. Dimensions of AGV are Length approx. $18 \mathrm{~m}$, Width approx. $1.8 \mathrm{~m}$, loading capacity—maximum 8 cars, Dead weight approx. 16,000 kg. Speed and Acceleration: Max. speed forward/reverse $40 \mathrm{~km} / \mathrm{hr}$, Maximum speed in curves $30 \mathrm{~km} /$ $\mathrm{hr}$, Maximum AGV steering speed $40 \mathrm{~km} / \mathrm{hr}$, Maximum acceleration $2 \mathrm{~m} / \mathrm{sec}^{2}$.

This AGV system uses electric power. Instead of getting electric power from outside, this AGV generates its own power. This paper proposes a solar powered AGV with a view to provide an environmentally friendly AGV. Electric motor drive allows faster maneuvers of AGV than diesel powered drive. Some vital aspects need to be considered in design of an AGV to meet the overall specifications. They are for steering control, electric motor power and battery energy capacity. The power concern of AGV is satisfied by solar cells. Generally, solar cells are prepared by using thin slices of gallium arsenide, crystalline silicon or other type of semiconductor materials. Solar cells directly convert the solar radiation from the sun into electricity. Cells with conversion efficiencies more than $30 \%$ are available now. By connecting more number of cells into modules, the cost of photo-voltaic

Fig.1 A model of AGV which is transporting cars

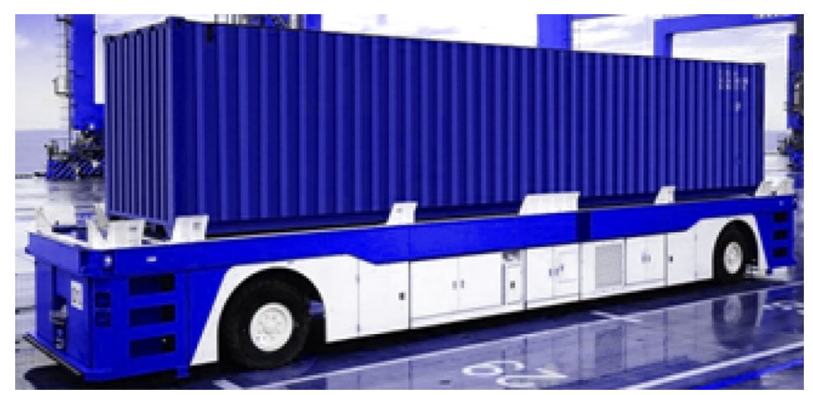


cell has been reduced to $30 \%$. In order to design the exterior shape of a solar AGV, three design considerations have to be considered. They are (1). The design must boost the quantity of surface area opened to sunlight to obtain maximum area. (2). The design of the solar AGV must have an aerodynamic shape to boost the quantity of drag to which the AGV is exposed. (3). AGV surface should have smooth gradual curves to have an aerodynamic body of low wind resistance.

Vehicle autonomy depends on its power source. AGV has batteries for power source. The operation time depends on the battery capacity. For longer time operation, power efficiency of the battery should be very high. $\mathrm{LiCoO}_{2}, 3.7 \mathrm{~V}, 200 \mathrm{~W}$ batteries are preferable. As per the specification of AGV, batteries can be arranged in series or parallel manner.

\subsubsection{AGV control system}

AGV has four wheels independent drive. Distributed control system method is used in AGV. The various parts of the AGV control system are motor controller module, driver module, wireless communication module, motor feedback module, navigation system module and vehicle control module. The motor driver drives the motor in $\mathrm{CW}$ or ACW direction and adjusts the amount of power flowing into the motor by receiving a signal from the motor controller. Motor controller system controls the movement of each motor actuator. The vehicle controller gives commands and reference signals to motor controller module. The signals have position and relative speed information to control the motor actuator. Motor control module gives signals to motor driver module as motor direction, on/off and motor brake. Also, power supplied to motor driver is controlled through a PWM generator. The rotary encoder's feedback signal is compared with a reference counter to control the vehicle. Based on the cumulative change in the position of the motor actuator, motor controller module frequently updates relative position data to the vehicle main controller. Motor control functions are done by control program software which is programmed in a digital processor. An example of a simple control algorithm is in Fig. 2.

3.1.2.1 Prime controller of AGV The function of the main controller of AGV is to set all modules. Based on commands received from the supervisory computer, it gives command to each motor control module. The commands are about the operations (loading, unloading and standby), path planning, target position, speed of movement, direction of the movement, etc. The prime controller also gives data about the AGV position updating to the supervisory computer. These AGV position data are used as a reference data by the supervisory computer to coordinate all AGVs. The prime function of a supervisory computer is coordinating and controlling the entire operation of all AGVs in the work place. To accomplish this, the major tasks of the supervisory computer are path planning, coordination and traffic management control. First, the supervisory computer gets all positional details of all the AGVs. It finds optimal path using some algorithms to each AGV. It sends information about optimal path to the main controller of AGV. The main controller of AGV directs the AGV along its optimal path. It updates the AGV positional details to the supervisory controller. The supervisory controller sends signal about changes or corrections to be done in the movement of AGV to avoid obstacles and collisions. Thus, each AGV moves in an optimal and safe path with help of the supervisory computer. The path planning algorithms used are cooperative method and priority method. A simple priority-based cooperative (PBC) AGVs control algorithm is detailed in Fig. 3. 


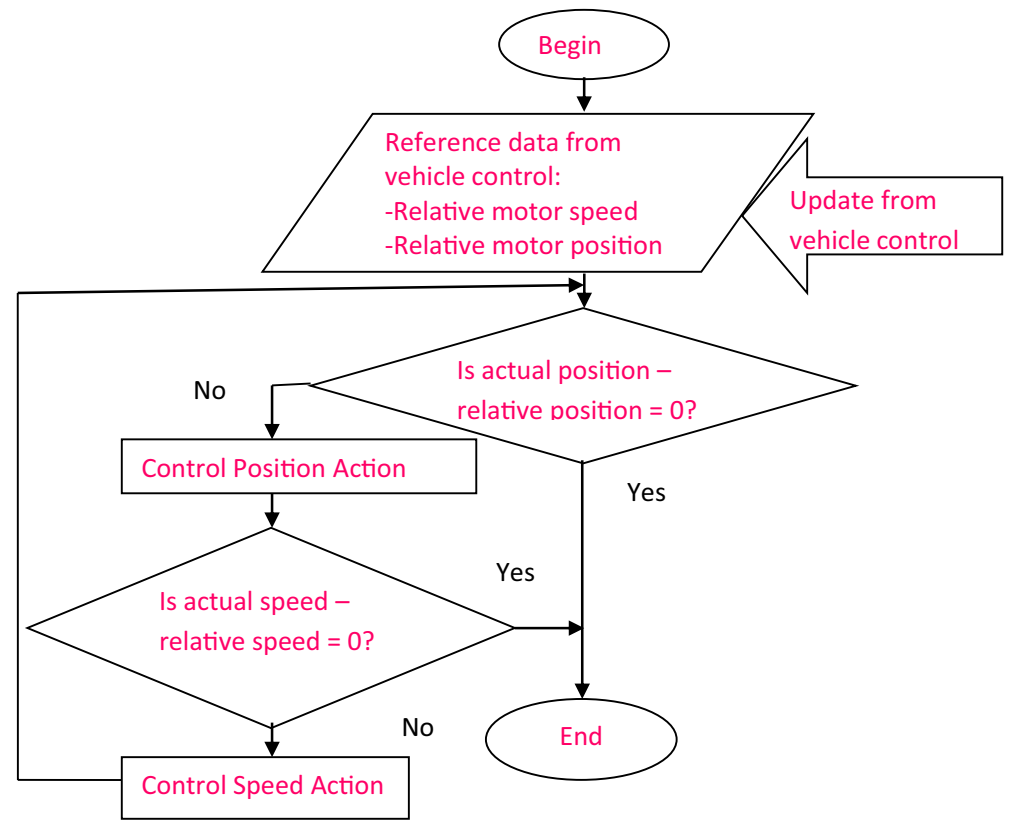

Fig.2 An algorithm for motor control module

The path planning is performed by cooperative method. First, the supervisory computer finds the optimal path of each AGV. It communicates it to the AGV. AGV moves along the path. The supervisory computer monitors the AGV movement and the environment around the AGV. As per the changes happening in the environment around the AGV, the supervisory computer changes the AGV movements (speed and direction of the movement). So the AGV gets safer movement to its goal location. Suppose two AGVs are moving along a same path, then based on priority for a task, the first priority AGV gets signal to move. Other AGV waits up to getting signal from the supervisory computer and then it moves. Thus, collision between AGVs is avoided.

The path planning algorithm of AGV finds final optimal path by the following stages:

Stage 1: Route planning: Finding the best routes to connect the origin and final stations. Stage 2: Path planning: Finding optimal path.

Stage 3: Maneuver planning: Finding an optimal maneuver for doing safe movement.

Stage 4: Trajectory planning: Finding optimal trajectory as per the constraints' satisfaction.

Stage 5: Trajectory tracking: Tracking the AGV accurately along the optimal trajectory.

\subsection{Strategy 2: multi-objective optimal design of RSC network}

\subsubsection{Problem formulation}

A new multi-objective optimization model of reverse supply chain with full valuation of emissions is considered in the problem to determine the optimal number of cars to be 


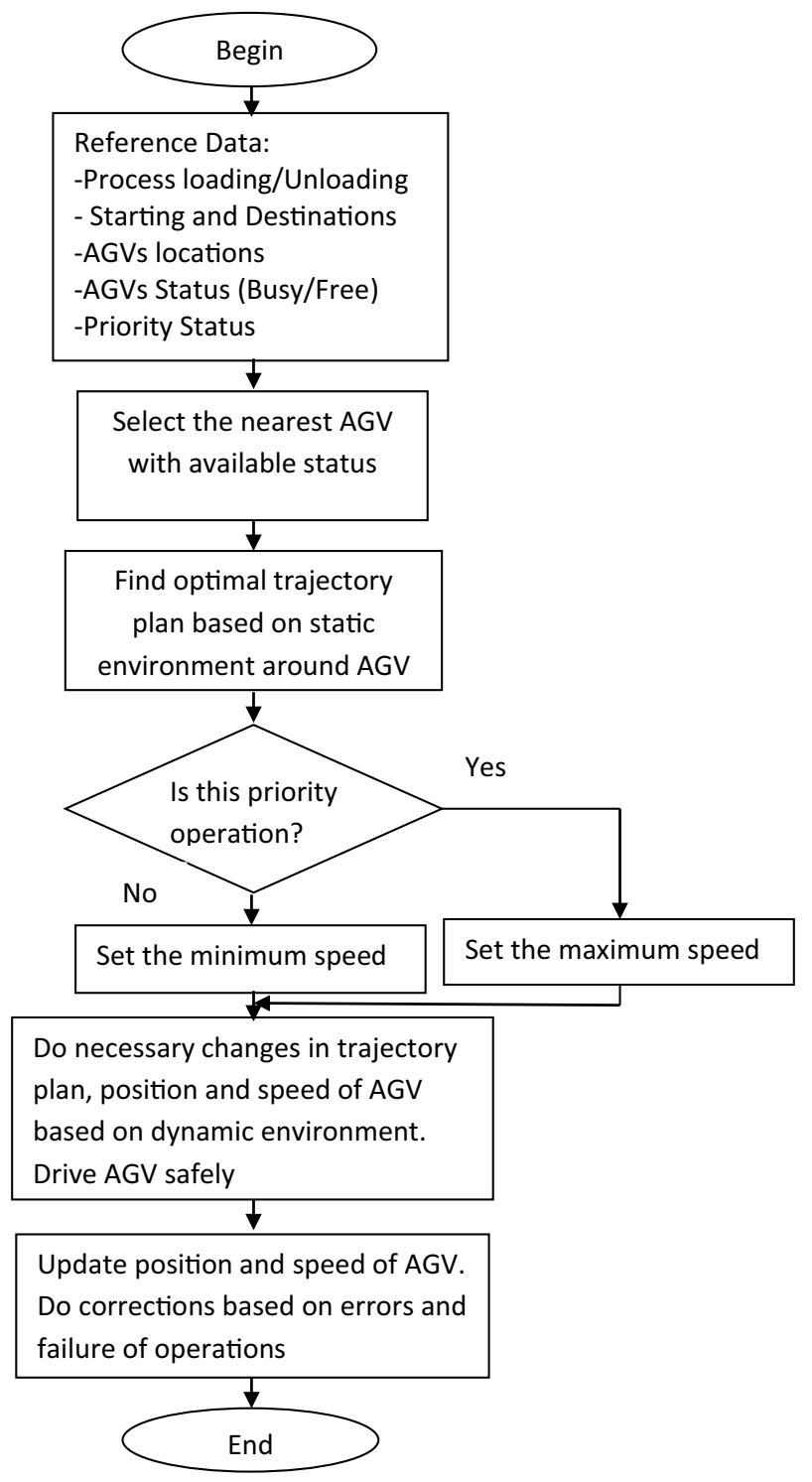

Fig.3 AGVs control algorithm-A simple PBC method

collected by all collection centers to reduce the total cost and GHG emissions. The total cost includes cost of energy, rent, labor, transportation, inventory, remanufacturing and product retrieval. GHG emissions and shortage cost are to be diminished.

Objective functions

$$
\begin{gathered}
\text { Minimize Total Cost }\left(F_{1}\right)=f_{1}+f_{2}+f_{3}+f_{4}+f_{5}+f_{6}+f_{7} \\
\text { Retrieval cost }\left(f_{1}\right)=R_{\mathrm{A}}\left(X_{1}+X_{2}+X_{3}+\ldots+X_{34}\right)
\end{gathered}
$$


Transportation cost $\left(f_{2}\right)$

$$
\begin{aligned}
= & \left(\left(87 X_{5}+90 X_{29}+55 X_{11}+59 X_{16}+62 X_{18}+61 X_{19}+45 X_{20}+99 X_{21}+75 X_{22}\right)\right. \\
& +\left(50 X_{33}+83 X_{34}+139\left(X_{4}+X_{5}\right)+49 X_{2}+74 X_{3}+39 X_{7}+24 X_{8}+71 X_{27}\right. \\
& +88\left(X_{28}+X_{29}\right)+58 X_{30}+77 X_{31}+164 X_{10}+64\left(X_{11}+X_{12}\right)+57 X_{13}+83 X_{15} \\
& \left.\left.+57\left(X_{17}+X_{18}+X_{19}+X_{20}+X_{21}+X_{22}\right)+101 X_{24}+57 X_{25}\right)\right) \mathrm{TC}
\end{aligned}
$$

Remanufacturing cost $\left(f_{3}\right)=R_{\mathrm{A}}\left(X_{1}+X_{2}+X_{3}+\ldots+X_{34}\right)$

$$
\text { Inventory cost }\left(f_{4}\right)=\left(\left(R_{\mathrm{A}}+P_{\mathrm{A}}\right) / 4\right)\left(X_{1}+X_{2}+X_{3}+\ldots+X_{34}\right)
$$

$$
\text { Rent cost }\left(f_{5}\right)=R C_{\mathrm{A}}\left(X_{1}+X_{2}+X_{3}+\ldots+X_{34}\right)
$$$$
\text { Labor cost }\left(f_{6}\right)=R L_{\mathrm{A}}\left(X_{1}+X_{2}+X_{3}+\ldots+X_{34}\right)
$$$$
\text { Energy cost }\left(f_{7}\right)=E C_{\mathrm{A}}\left(X_{1}+X_{2}+X_{3}+\ldots+X_{34}\right)
$$

$$
\begin{aligned}
\text { Minimize GHG Emissions }\left(F_{2}\right) \\
=\left(G H_{\mathrm{C}}+G H_{\mathrm{R}}+G H_{\mathrm{S}}\right)\left(X_{1}+X_{2}+X_{3}+\ldots+X_{34}\right) \\
\quad+\left(G H _ { \mathrm { T } } * k g * \left(\left(87 X_{5}+90 X_{29}+55 X_{11}+59 X_{16}+62 X_{18}+61 X_{19}+45 X_{20}+99 X_{21}+75 X_{22}\right)\right.\right. \\
\quad+\left(50 X_{33}+83 X_{34}+139\left(X_{4}+X_{5}\right)+49 X_{2}+74 X_{3}+39 X_{7}+24 X_{8}+71 X_{27}+88\left(X_{28}+X_{29}\right)\right. \\
\quad+58 X_{30}+77 X_{31}+164 X_{10}+64\left(X_{11}+X_{12}\right)+57 X_{13}+83 X_{15}+57\left(X_{17}+X_{18}+X_{19}\right. \\
\left.\left.\left.\left.\quad+X_{20}+X_{21}+X_{22}\right)+101 X_{24}+57 X_{25}\right)\right)\right)
\end{aligned}
$$

Minimize Shortage $\operatorname{cost}\left(F_{3}\right)=\left(T D-\left(X_{1}+X_{2}+X_{3}+\ldots+X_{34}\right)\right) S C_{\mathrm{C}} *(1-D)$

If $\left(\mathrm{X}_{1}+\mathrm{X}_{2}+\mathrm{X}_{3}+\ldots+\mathrm{X}_{34}\right) \leq \mathrm{TD}$, then there is no shortage, so $D=1$, Else $D=0$.

Minimize Combined objective function $(F)=W_{1} * F_{1} / N_{1}+W_{2} * F_{2} / N_{2}+W_{3} * F_{3} / N_{3}$

$\mathrm{W}_{1}, \mathrm{~W}_{2}, \mathrm{~W}_{3}$ are weightage given to each objective function. More weightage is given to reduce GHG emissions. So, $W_{1}=W_{3}=0.3, W_{2}=0.4$.

$\mathrm{N}_{1}, \mathrm{~N}_{2}, \mathrm{~N}_{3}$ are normalizing parameters to bring all objective functions in same range. $N_{1}=10^{9}, N_{2}=10^{5}, N_{3}=1$.

\section{Constraints}

The total cost of inventory and production $\leq$ Total resale cost.

$$
C_{1}=C\left(X_{1}+X_{2}+X_{3}+\ldots+X_{34}\right)=T C
$$

To utilize fully the repairing facility, the input to a repairing center should be greater than its capacity.

$$
C_{2}=\left(X_{1}+X_{2}+X_{3}+\ldots+X_{34}\right) \geq T R C
$$


The space occupied for collection of cars should be optimum. So, total space used for collection of cars needs to be less than the total space available for collection of cars.

$$
\begin{aligned}
C_{3} & =\text { (space required/car) }\left(X_{1}+X_{2}+X_{3}+\ldots+X_{34}\right) \leq T S_{\mathrm{C}} \\
& =\text { Total space available at all collection centers }
\end{aligned}
$$

The space occupied for repairing cars should be optimum. So, total space used for repairing of cars needs to be less than the total space available for repairing of cars.

$$
\begin{aligned}
C_{4} & =(\text { space required for repair/car })\left(X_{1}+X_{2}+X_{3}+\ldots+X_{34}\right) \leq T S_{\mathrm{R}} \\
& =\text { Total space available at all major repair centers }
\end{aligned}
$$

The space occupied for resale of cars should be optimum. So, total space used for resale of cars needs to be less than the total space available for resale of cars.

$C_{5}=($ space required $/ \mathrm{car})\left(X_{1}+X_{2}+X_{3}+\ldots+X_{34}\right) \leq T S_{\mathrm{S}}=$ Total space available at all resale centers

Total GHG emissions need to be less than Carbon strict cap limit

$$
C_{6}=T G H G \leq C A C
$$

Variables bounds.

$$
\begin{gathered}
C_{7}=X_{1}, X_{2}, X_{3}, \ldots, X_{34} \geq 0 \\
C_{8}=X_{1}, X_{2}, X_{3}, \ldots, X_{34} \leq 50
\end{gathered}
$$

Total number of cars supplied to repairing facilities by collection centers is at most the supply

$$
C_{9}=\left(X_{1}+X_{2}+X_{3}+\ldots+X_{34}\right) \geq \mathrm{TMC}
$$

Total number of cars supplied to resale centers by major repair shops is at most the supply

$$
C_{10}=\left(X_{1}+X_{2}+X_{3}+\ldots+X_{34}\right) \geq \mathrm{TCC}
$$

Variables

The cars are to be transferred from all collection centers to repair shops and also from repair shops to resale centers. Number of used-cars collected at 34 collection centers are denoted by $X_{1}, X_{2}, X_{3}, \ldots, X_{34}$. Where, $X_{1}$ means number of used-cars to be collected at city number 1 .

\subsubsection{Assumptions}

Assumptions made in this research work are as follow:

From four sources, GHG emissions come. They are:

1. Collection centers: Here, emission quantity is equivalent to the power consumption.

2. Repairing centers: Here, emission quantity is equivalent to volume of repairing facilities in these centers. 
3. Reselling centers: Here, emission quantity is calculated by these centers' power consumption.

4. Transportation of used cars: Here, the emission quantity is calculated by the distance traveled between centers.

The average weight of each car is assumed as $2000 \mathrm{~kg}$. The inventory cost in each collection centre is $25 \%$ of its retrieval cost $(R)$. Also, it is same in each repair shop, i.e., $25 \%$ of its reprocessing cost $(P)$.

\section{Application of proposed optimization model}

The proposed multi-objective optimization model is tested for a real-world problem. RSC network design for Maruti True Value Company is taken as the problem. This RSC network design is for optimizing the resale of used cars of Maruti Suzuki Company in Tamil Nadu and Puducherry region, India. Maruti True Value Company has 34 collection centers from various locations in Tamil Nadu and Puducherry region. The used cars collected in collection centers are sent to repair workshops. If required, they are sent for major workshops. After necessary repair and replacement works, the cars are sent to major resale centers. The actual problem of the company is to reduce its cost spending and to increase its profit. Also, GHG emissions from various sectors of the company have to be reduced to the allowable limit. The ideal case is a situation in which GHG emissions are zero.

\subsection{Questionnaire preparation}

Questionnaires were designed to get initial data related to location details of Maruti True Value collection centers, major workshops and major resale centers. Survey form model is given in Appendix. Questions are asked for getting the details about car models, their prices, performance characteristics, physical dimensions such as length, breath, height and weight, engine performance and emissions, major problems associated with Maruti Suzuki cars, showrooms details like space available for collection, repair and resale of cars, number of labors and their salary details, energy conservation details (Electricity bills), customers' opinions about car resale requirements, retrieval costs, repair costs, transportation facilities, transportation costs, GHG emissions during transportation, allowed GHG emissions stated by Government agencies, used cars' collection details, repair works details, resale details, facilities available for repair works, maximum capacity to collect, repair and resale cars. Questionnaires were given to 200 peoples. They are contacted in person, through email and phone calls. People contacted are the managers, supervisors, office people and labors of Maruti True Value Company. 124 people gave the above details. Time spent for collecting details is three months.

The following details are also collected from them: Average Retrieval cost/car, Average Processing cost/car, Transportation cost $/ \mathrm{km}$, Average rent cost for all centers/year, Average labor cost/year, Average energy cost/year, Average GHG emissions at collection centers/year, Average GHG emissions at major repair shops/year, Average GHG emissions at major resale centers/year, Average GHG emissions from a car carrying truck/km, Maximum weight of a car, Total demand of resale cars, Total repairing capacity, Shortage cost per car at collection centre, Total space for collection of used cars, Total space for repairing cars, Total space for resale of cars, Carbon strict cap (CSC) allowable, Total 


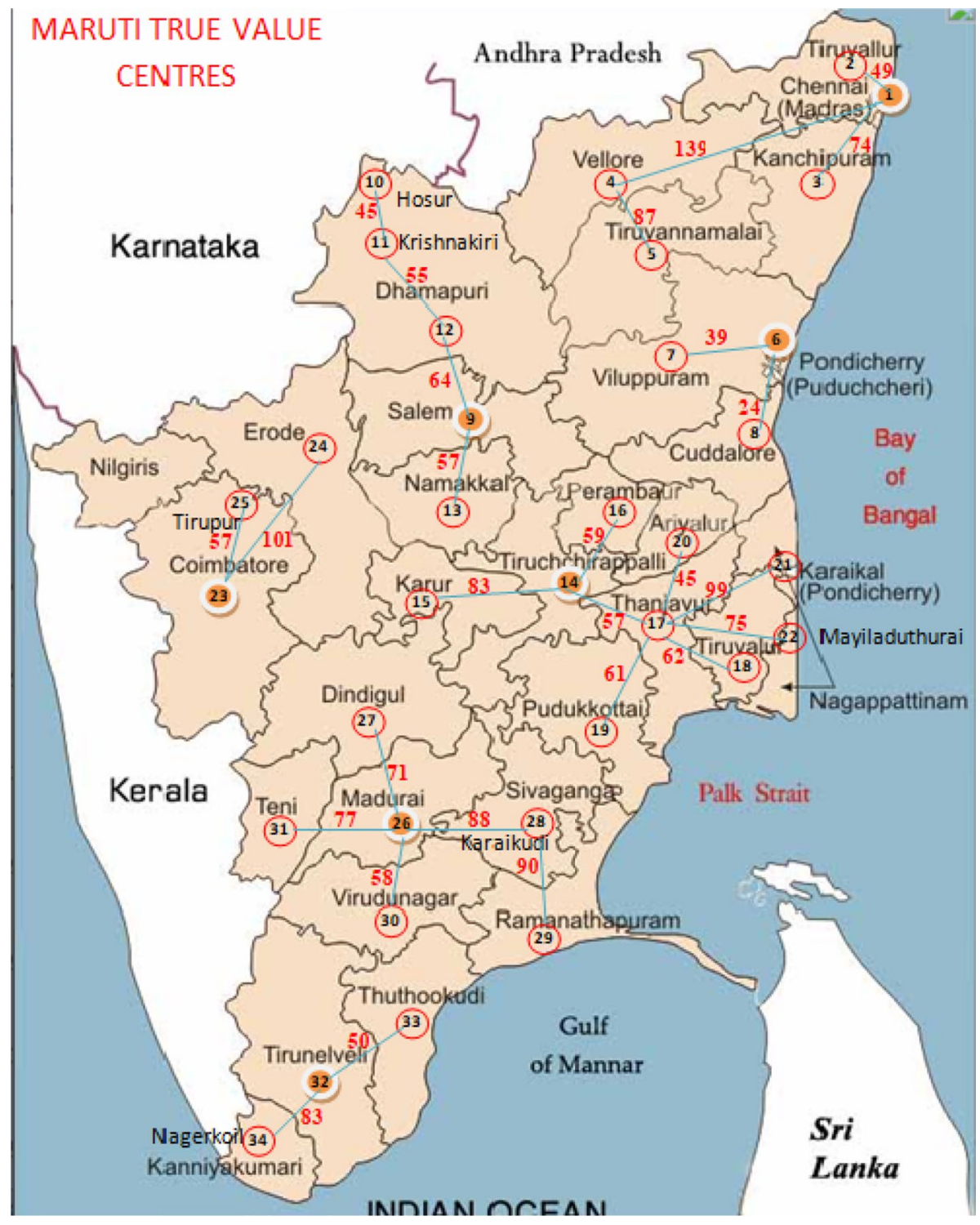

Fig.4 Maruti True value centers details

remanufacturing facility capacity, Total collection centers capacity, Cost of production and inventory/car and Total resale cost.

\subsection{Data collection}

The used cars' collection centers are located in the cities listed in Fig. 4. The distance from collection centers to nearby major repair workshops is shown in Fig. 4. Also, the distance from major repair workshops to nearby major resale centers is shown in Fig. 4. 
Collection centers' City Names with City number are Chennai (1), Tiruvallur (2), Kanchipuram (3), Vellore (4), Tiruvannamalai (5), Puducherry (6), Vilupuram (7), Cuddalore (8), Salem (9), Hosur (10), Krishnagiri (11), Dharmapuri (12), Namakkal (13), Trichy (14), Karur (15), Perambalur (16), Tanjore (17), Tiruvarur (18), Pudukkotai (19), Ariyalur (20), Karaikal (21), Myladuthurai (22), Coimbatore (23), Erode (24), Tirupur (25), Madurai (26), Dindigul (27), Karaikudi (28), Ramanathapuram (29), Virudhunagar (30), Theni (31), Tirunelveli (32), Tuticorin (33) and Nagerkoil (34).

The major workshops for doing repair works are located in cities listed below: Chennai (1), Tiruvallur (2), Kanchipuram (3), Vellore (4), Tiruvannamalai (5), Puducherry (6), Vilupuram (7), Cuddalore (8), Salem (9), Hosur (10), Dharmapuri (12), Namakkal (13), Trichy (14), Karur (15), Tanjore (17), Coimbatore (23), Erode (24), Tirupur (25), Madurai (26), Dindigul (27), Karaikudi (28), Virudhunagar (30), Theni (31), Tirunelveli (32), Tuticorin (33) and Nagerkoil (34).

Major resale centers are located in the following cities: Chennai (1), Puducherry (6), Salem (9), Trichy (14), Coimbatore (23), Madurai (26) and Tirunelveli (32).

\section{Proposed optimization methods}

Generally, traditional optimization methods yield sub-optimal results. But intelligent optimization algorithms yield optimal solutions. Especially evolutionary algorithms viz., genetic algorithm (GA), Elitist Nondominated Genetic Algorithm (NSGA-II), Differential Evolution (DE), etc., provide optimal solutions. The resulted optimal solution chances to be global optima. The effective and robust nature of these evolutionary algorithms makes them the best fit for the multi-objective optimization problems. Few researchers used GA (Hamid Afshari et al. 2016) and artificial immune system (Diabat et al. 2013a, b) for optimal design of a RSC network. In this research work, both HMODE and NSGA-II algorithms are used for optimal design of a RSC for Maruti True Value Company. To select the best optimal solution from the Pareto-optimal front, normalized weighted objective functions (NWOF) method is used. The strength or weakness of a Pareto-optimal front is evaluated by metrics-ratio of non-dominated individuals (RNI) and solution spread measure (SSM). Also, Algorithm Effort (AE) and Optimiser Overhead (OO) are utilized to find the computational effort of multi-objective optimization algorithms.

\subsection{NSGA-II}

NSGA-II is a variant of GA (Genetic Algorithm), and it is a most popular algorithm for an optimization problem with multi-objectives (Deb et al 2002). Major differences between NSGA and NSGA-II are as follow: (1) Elitism principle is implemented in the NSGA-II for preserving good solutions found in previous iterations. (2) The sorting procedure of the NSGA-II is faster than that of NSGA. (3) The tuneable parameter is not needed in NSGAII. So, NSGA- II algorithm does not depend on the programmer. Figure 5 shows the procedural flowchart of NSGA-II algorithm. 


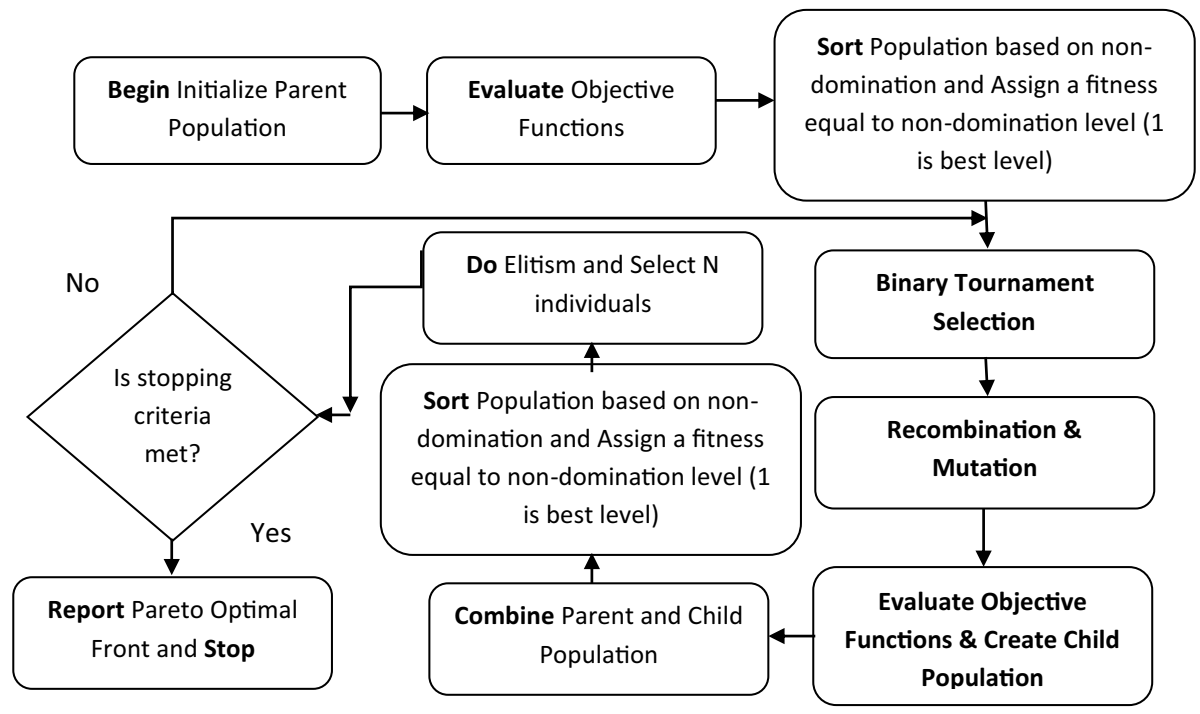

Fig.5 The procedural flowchart of NSGA-II

\subsubsection{NSGA-II operators}

NSGA-II parameters value are: population size is 100 , variable type is real variable, crossover probability is 0.7 , real-parameter mutation parameter and probability are 100 and $0.01, \mathrm{SBX}$ value of real-parameter is 10 , maximum no. of generations is 100 .

\subsection{Heterogeneous MODE (HMODE)}

MODE algorithm is a very good MOO algorithm. But, it has a few demerits (Thangavelu et al. 2015). They are (1) it uses only one scheme like DE/rand/1/bin for generating a new solution. But a lot of schemes are available. Also, the best-performing schemes such as DE/current-to-best/1(Zhang and Sanderson 2009), DE/TSDE(Sathiya and Chinnadurai 2019), and DE/rand-to-best/1(Qin et al. 2009) are not used by MODE. (2) The value of scaling factor (SF) is not changed throughout all iterations. If SF value changes in all iterations, the best solutions are generated.

Differential evolution (DE) is a good algorithm to solve optimization problems. DE is superior to solve complex multi-model real-world problems in all fields of engineering and science. A new DE variant is produced by changing the differential mutation scheme. A lot of schemes are available for creating new solutions or doing differential mutation to create a noisy vector, so a lot of DE variants are available. To generate a global optimal result, all the requirements, effectiveness and efficiency are to be associated with a DE variant. At present, no single DE variant can generate global optimal solutions for most real-world MOO problems. All the schemes have their own merits and demerits. An idea proposed by (Thangavelu et al. 2015) is combining two to five best performing variants. The new DE variant name is heterogeneous DE. HDE works in an island-based distributed solution structure. An analysis to find the merits and demerits of HDE was done by (Thangavelu et al. 2015). They performed many 
experiments using a distributed framework and finally found that HDE was superior in generating global solutions.

However, HDE has some demerits. They are (1) only 4 simple DE variants namely DE/ rand/1/bin, DE/best/1/bin, DE/best/2/bin and DE/rand/2/bin were used. Best-performing and important variants such as DE/current-to-best/1, DE/TSDE and DE/rand-to-best/1 were not used. (2) Further, a real-world MOO problem was not solved by them. (3) A constrained problem was not solved by them. They did not consider any constraints in their problems. (4) They solved only single objective simple problems. They had not solved a real-world MOO problem. (5) Scaling factors K and SF were constant values.

To eradicate the demerits of HDE proposed by (Thangavelu et al. 2015), a new variant HMODE is proposed in this research work. The advantages of the proposed HMODE algorithm are detailed below: (1) Best-performing and important variants such as DE/currentto-best/1, DE/TSDE and DE/rand-to-best/1 are used. (2) Real-world MOO problems are solved. (3) A constrained problem is solved. Seven constraints were considered in the problems solved in this research work. (4) Real-world MOO problems are solved by proposed HMODE. (5) Scaling factors $\mathrm{K}$ and SF are flexible. They were randomly created in all iterations. (6) An improved crossover method is used in HMODE.

Figure 6 explains the pseudocode of the proposed HMODE. Figure 7 details how to implement and use the proposed HMODE for solving a real-world MOO problem.

\subsubsection{HMODE operators}

The recommended values (Thangavelu et al. 2015) for HMODE parameters are crossover constant $(\mathrm{CC})=0.1-0.95$, number of population (NP) of 100, Max. number of generations $=100$.

\subsection{Ratio of non-dominated individuals (RNI)}

The first necessary condition for a good Pareto-optimal front is more no. of solutions. RNI checks this condition. According to RNI, the algorithm which results in more no. of solutions is the best algorithm.

RNI can be had from the equation:

$$
\operatorname{RNI}(X)=\text { nondom_indiv } / P
$$

nondom_indiv $=$ total no. of non-dominated solutions found by the algorithm, $P=$ population size. RNI gets the value as 1 , when all the solutions in the Pareto front are non-dominated solutions. RNI gets the value as 0 , when all the solutions in the Pareto front are not non-dominated solutions. Both are rare cases. So always $R N I=0-1$. The best MOO algorithm will result in a high RNI value.

\subsection{Solution spread measure (SSM)}

The second necessary condition for a good Pareto-optimal front is good spread of solutions in all sectors of solution space. Hence, the user gets more choice of solutions in all sectors. SSM checks this condition. According to SSM, the algorithm which results in a good spread of solutions is the best algorithm.

SSM can be had from the equation 


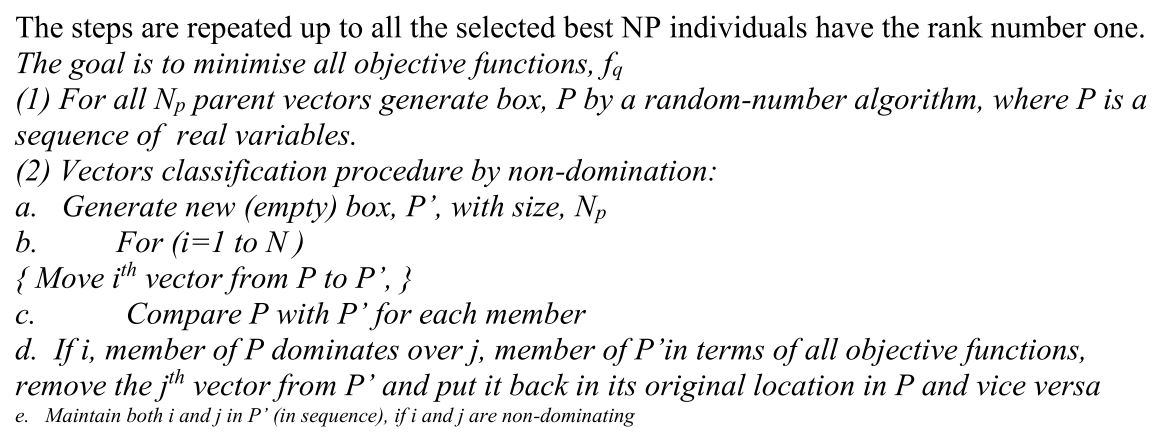

$f$. Repeat the above procedure for all the vectors in $P$. Now $P^{\prime}$ contains a sub-box called first front. It is a subset of $P$ contains non-dominated vectors. Assign a rank number, $I_{\text {rank, }}$ of $I$

g. Repeat step $2 b$ above (for the vectors remain in $P$ ), create subsequent fronts. Assign ranks for the subsequent fronts generated, $I_{\text {rank }}=2,3 \ldots$ Thus, the box $P^{\prime}$ is a sequence of fronts generated by all $N_{p}$ vectors .

(3) Spreading out: Procedure to calculate crowding distance, $I_{i, d i s t}$. It is a distance from $i^{\text {th }}$ vector which is from any front, $j$, of $P^{\prime}$ :

Arrange all vectors in front $j$ sequentially to define the nearest neighbor of any vector in the front. The vectors are arranged in a ascending fashion based on objective functions like fitness functions.

b. Find the cuboid of largest size which encloses vector $i$ that nearly touches its very nearest neighbors in f-space.

c. Calculate $I_{i, \text { dist }}=1 / 2 *($ sum of all the sides of the cuboid $)$

$d$. The values of largest Ii, dist are solutions at boundaries. It influences the convergence characteristics.

(4) Do the DE operation on NP target vectors present in the P' to generate a NP trial vectors, then save it in $P^{\prime \prime}$.

a. Generate new (empty) box, $P$ ', of size $N_{p}$

For $(i=1$ to $N)$, in $P^{\prime}$, allocate solutions to sub populations NP/5, where each node has $\mathrm{NP} / 5$ solutions

Fig. 6 a HMODE Pseudocode b HMODE Pseudocode

$$
\mathrm{SSM}=\frac{d_{f}+d_{l}+\sum_{i=1}^{N-1}\left|d_{i}-\bar{d}\right|}{d_{f}+d_{l}+(N-1) \bar{d}}
$$

$N=$ number of Pareto-optimal solutions in Pareto fronts. $N-1$ consecutive distances are available here, $d_{i}=$ the distance between two adjacent solutions (in objective function space), $\bar{d}=$ arithmetic mean value by considering all solutions' distances $d_{i}$. $d_{l}=$ Euclidean distance in between two extreme solutions available in the Pareto-optimal front. $d_{f}=$ Euclidean distance in between two boundary solutions. When there is a very good distribution of non-dominated solutions in the Pareto-optimal front offered by an algorithm, then the SSM value is very small. When there is a very bad distribution of non-dominated 


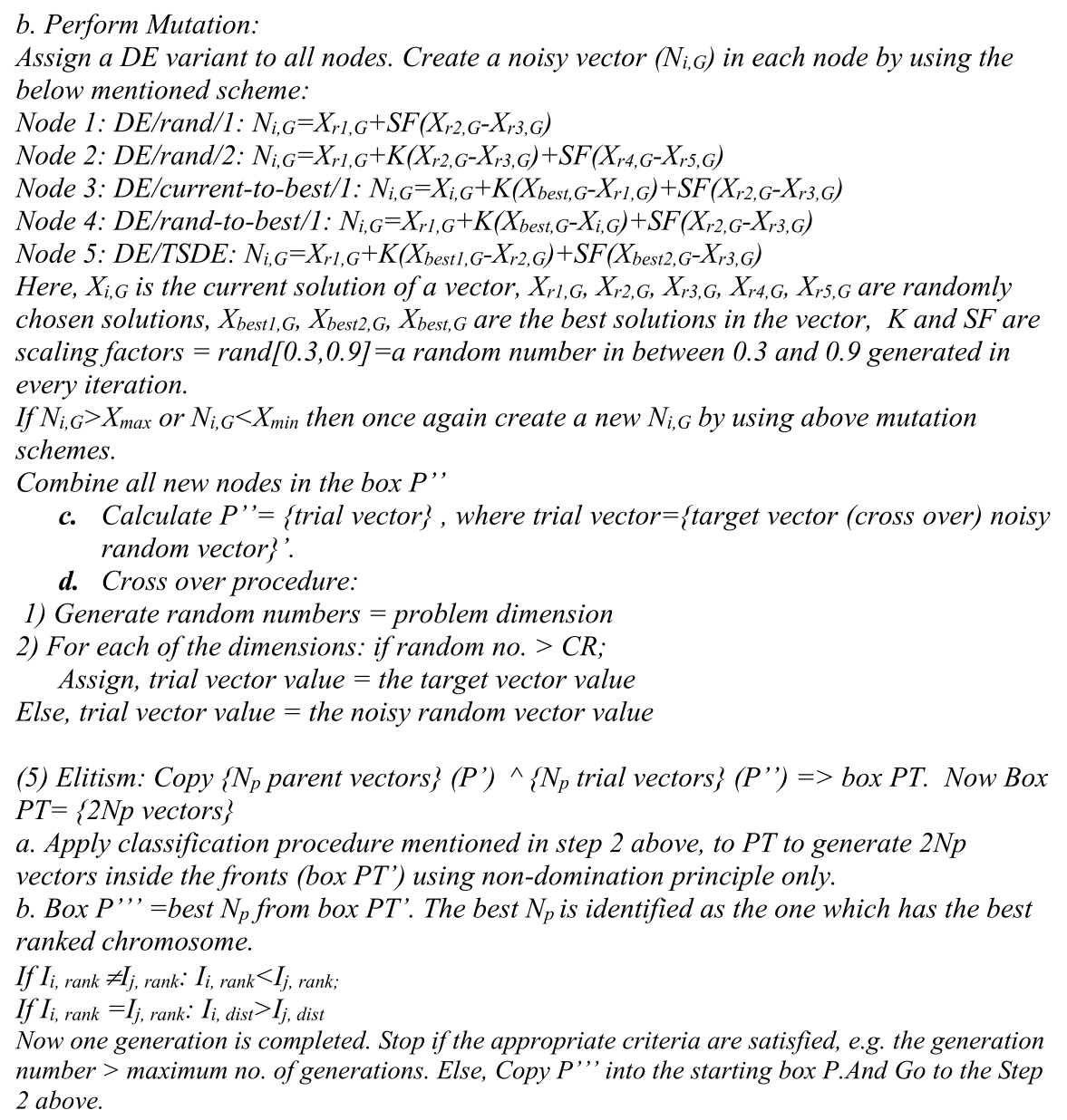

Fig. 6 (continued)

solutions in the Pareto-optimal front offered by an algorithm, then the SSM value is very high. So, SSM finds the distribution strength of non-dominated solutions along the Paretooptimal front. The best algorithm's SSM value is very low.

\subsection{Optimiser overhead (00)}

Total time complexity and total no. of functions assessments are the two parameters related the computer and employed to analyze an algorithm's effectiveness. By these parameters, for an algorithm, no. of calculations made, the simplicity, time spent to solve the problem and memory requirements can be analyzed. The best algorithm has a less no. of calculations, simple structure, less memory requirement and less running time. OO can be had from the equation 


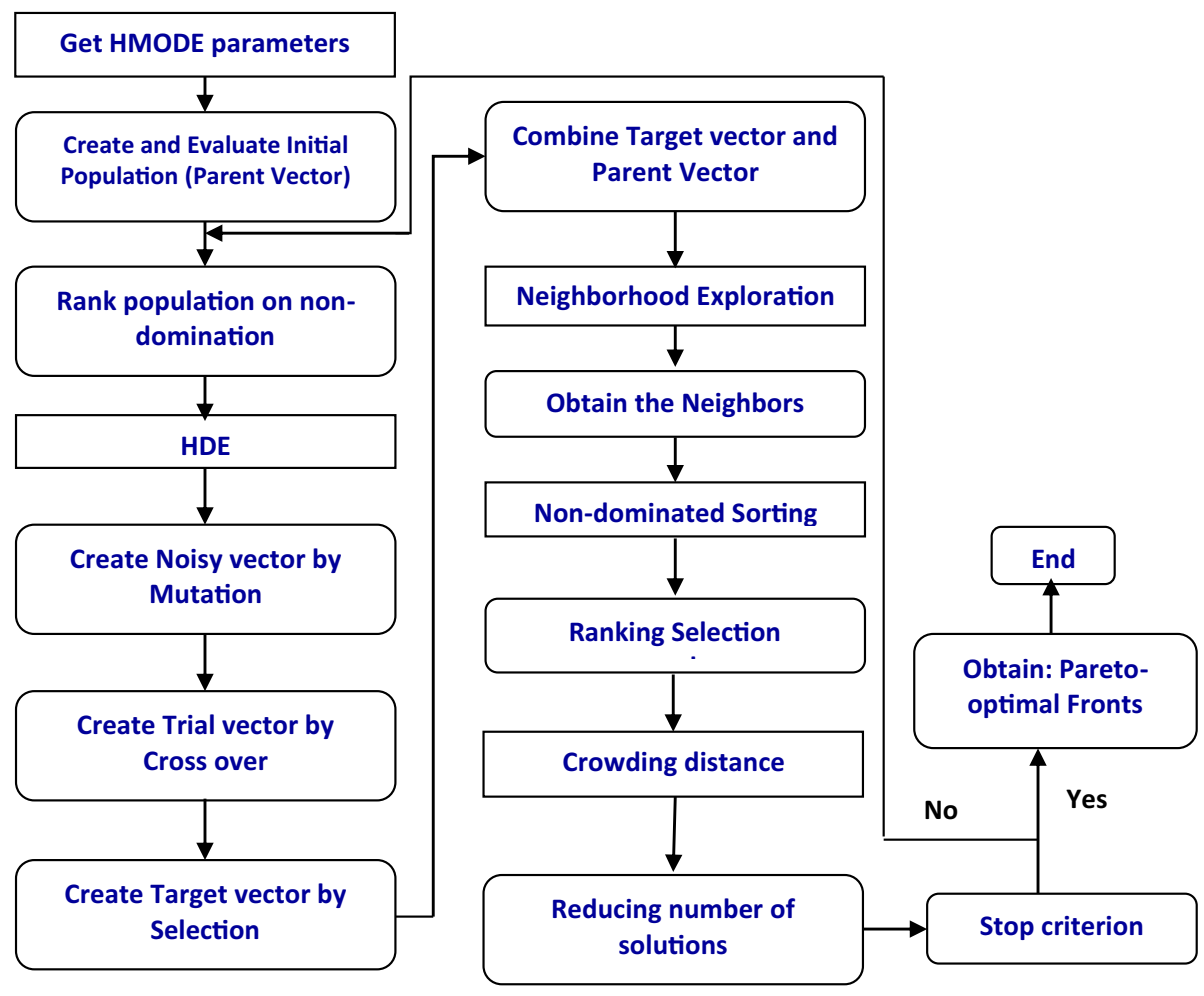

Fig.7 Procedure of implementing HMODE

$$
O O=\left(T_{\text {Total }}-T_{\mathrm{PFP}}\right) / T_{\mathrm{PFP}}
$$

In the above equation, $T_{\text {Total }}=$ Total time spent on finding the results. $T_{\mathrm{PFP}}=$ Time spent for evaluating only pure functions. $\mathrm{OO}$ is 0 for the best algorithm. It means that there is no overhead for the algorithm. But it is not possible.

\subsection{Algorithm effort (AE)}

AE calculates an algorithm's computational efficiency to result in non-dominated solutions. AE dictates how many functions of the problem are calculated by an algorithm in a fixed time sample. AE can be had from the equation.

$$
\text { Algorithm Effort }=T_{\text {run }} / N_{\text {eval }},\left(T_{\text {run }}>T_{1 \text { stgen }}\right) \cap\left(T_{\text {eval }} \propto N_{\text {eval }}\right)
$$

In the above equation, $N_{\text {eval }}$ is the total no. of functions solved. $T_{\text {run }}$ is a sample time. In general, the method to find the sample time is $T_{\text {run }}>T_{1 \text { stgen. }} T_{1 \text { stgen }}$ is first-generation computation time. $T_{\text {run }}$ and $N_{\text {eval }}>0$. Practically, $A E=(0, \infty)$. The best algorithm will solve the maximum no. of functions in the sample time. This is due to the reality that the computational effort of the best algorithm is very high. $A E$ value of the best algorithm will be small. 


\section{Results and discussion}

\subsection{Strategy 1 -solar powered AGV}

Market internationalization and climate change are creating multiple problems for modern Supply Chain (SC) management in today's digitized era. On the other side, AGVs have reached maturity. So they can be used to cope with dynamic market conditions. With sustainability considerations, they can align with the SC management approach. Bechtsis et al. (2017a) and Guilherme T Aguiara et al. (2019) detailed more applications of AGVs in SC. This research work promotes sustainability potential of AGVs, focusing more on reverse logistics supply chain in a used-cars resale industry for promoting environmental, economic and social sustainability. The advantages of solar energy are: it is a renewable energy, environment-friendly energy, economy-friendly energy, infinite energy, innovative energy (more innovations are happening in design of solar cells and systems) and longterm energy. In this research work, the aim is to design an eco-friendly and sustainable AGV. So, solar powered AGV is suggested in this work.

Schmidt et al. (2015) showed that AGVs reduce GHG emissions like $\mathrm{NO}_{2}$ and $\mathrm{CO}_{2}$. If AGVs are used instead of car carrier trucks, GHG emissions due to transportation can be reduced to zero. The ultimate aim is reducing GHG emissions to zero. So this strategy suggests using a solar powered AGV instead of car carrier truck. The cost of AGV depends upon its type. The estimated cost of the proposed solar powered AGV in this work is approximately $\$ 9500$ including all accessories.

\subsection{Strategy 2-multi-objective optimization of RSC}

The RSC is a major solution to get environment friendly goods and to increase the endof-life products (Piyawat Chanintrakul et al. 2009). It gives benefits related to the environment and economic and also influences costs, emissions during transportation, collection, recovery facilities, recycling, disassembly, remanufacturing and removal of reusable components (Alkhayyal and Gupta 2018). RSC management problem of a used-cars resale company is investigated in this research. Few assumptions are made in the problem. They are as follow: Average Retrieval cost/car $\left(\mathrm{R}_{\mathrm{A}}\right)=\$ 1000$, Average Processing cost/ car $\left(\mathrm{P}_{\mathrm{A}}\right)=\$ 10,000$, Transportation cost $/ \mathrm{km}(\mathrm{TC})=\$ 2$, Average rent cost for all centers/ year $\left(\mathrm{RC}_{\mathrm{A}}\right)=\$ 100,000$, Average labor cost/year $\left(\mathrm{LC}_{\mathrm{A}}\right)=\$ 720,000$, Average energy cost/ year $\left(\mathrm{EC}_{\mathrm{A}}\right)=\$ 12,000$, Average GHG emissions at collection centers/year $\left(\mathrm{GH}_{\mathrm{C}}\right)=0.02$ $\mathrm{tCO}_{2} \mathrm{e}$, Average GHG emissions at major repair shops/year $\left(\mathrm{GH}_{\mathrm{R}}\right)=0.12 \mathrm{tCO}_{2} \mathrm{e}$, Average GHG emissions at major resale centers/year $\left(\mathrm{GH}_{\mathrm{S}}\right)=0.02 \mathrm{tCO}_{2} \mathrm{e}$, Average GHG emissions from a car carrying truck/ $\mathrm{km}\left(\mathrm{GH}_{\mathrm{T}}\right)=0.005 \mathrm{tCO}_{2} \mathrm{e}$, two trucks are used for transportation. The prescribed car carrier truck length as per India's Central Motor Vehicle Regulations (CMVR) is $18 \mathrm{~m}$. Maximum 8 cars can be accommodated in a truck. Maximum weight of a car $(\mathrm{kg})=2000 \mathrm{~kg}$. Total demand of resale cars $(\mathrm{TD})=1200$. Total repairing capacity $(\mathrm{TRC})=1200$, Shortage cost per car at collection centre $\left(\mathrm{SC}_{\mathrm{C}}\right)=\$ 100$. Total space for collection of used cars $\left(\mathrm{TS}_{\mathrm{C}}\right)=15000 \mathrm{~m}^{2}$. Total space for repairing cars $\left(\mathrm{TS}_{\mathrm{r}}\right)=15000 \mathrm{~m}^{2}$. Total space for resale of cars $\left(\mathrm{TS}_{\mathrm{S}}\right)=16000 \mathrm{~m}^{2}$. Total GHG emission (TGHG) is as per calculation. Carbon strict cap (CSC) allowable $=2 \mathrm{X} 0^{5} \mathrm{tCO}_{2} \mathrm{e}$. Total remanufacturing facility capacity $(\mathrm{TMC})=1200$. Total collection centers capacity $(\mathrm{TCC})=1200$. Cost of production and inventory/car $(C)=\$ 1500$. Total resale cost $(\mathrm{TC})=\$ 25,00,000$. 
Evolutionary algorithms belong to global optimizer category. Since they suit well to complex and multi-dimensional problems. Often, they yield global optima. They are suitable to deal with noisy-evaluation functions and complex functions. They are yielding a good no. of sensible solutions within less time. They can solve any type of problem. So, they can be used in all fields. Evolutionary algorithm optimizers are global optimization methods and scale well to higher dimensional problems (Hamid Afshari et al. 2016). They are robust with respect to noisy evaluation functions, and the handling of evaluation functions which do not yield a sensible result in a given period of time. Basic evolutionary algorithms may not yield global optima solutions (Diabat et al. 2013a, b). But, by improving their schema and structure, they can yield global optima results (Sathiya and Chinnadurai 2019). Such a try is done in this work by proposing HMODE algorithm.

All real-world problems have unequal and conflicting objectives (Sathiya and Chinnadurai 2019). Also, all objectives are needed simultaneous optimization. In the case of single-objective optimization (SOO), there is a clear definition of an optimal solution. But, multi-objective optimization (MOO) does not yield exact optimal solution. Instead of having a single optimum solution, there is a set of equally important solutions called as nondominated solutions. If all objective functions are considered, then there is no better solution available in the search space than these solutions. These solutions are superior to any other solutions available in the search space. Among the non-dominated solutions, no solution is better than another solution. These solutions are equally important solutions. These trade-off solutions are also called as Pareto-optimal solutions. The line or curve which connects all these Pareto-optimal solutions is called as Pareto front. In the problem considered in this research work, the user needs trade-off solutions. So, a multi-objective optimization is considered in this research. The problem is solved as MOO problem by both HMODE and NSGA-II. The MOO of RSC of Maruti True Value Company is solved by NSGA-II and HMODE algorithms. So, both algorithms gave trade-off solutions. Figure 8 illustrates the non-dominated solutions from both NSGA-II and HMODE. NSGA-II offered 44 tradeoff solutions. But HMODE offered only 36 trade-off solutions. So, NSGA-II gives more number of non-dominated solutions. For getting more trade-off solutions, NSGA-II is preferred to HMODE.

On the basis of giving suitable weightage to all objective functions, the best trade-off solution is selected from the solutions yielded by both HMODE and NSGA-II. For this, combined objective function (COF) method is used. The results obtained from NSGA-II and HMODE techniques are tabulated in Tables 1, 2, 3, 4, 5, 6. Table 1 shows the optimal value of number of cars to be collected by all Collection centers per year. The optimal variables values (minimum number of reused cars to be collected per year in all collection centers to get minimal costs, GHG emissions and shortage cost) are dictated by both algorithms. From Table 1, the following points are to be satisfied: (a) Chennai, Tiruvallur, Puducherry, Vilupuram, Cuddalore, Namakkal, Trichy, Coimbatore, Madurai, Tirunelveli and Tuticorin centers need to get cars in the range of 40-48. (b) Kanchipuram, Tiruvannamalai, Dharmapuri, Karur, Perambalur, Tanjore, Tiruvarur, Pudukkotai, Ariyalur, Myladuthurai, Tirupur, Dindigul, Karaikudi, Ramanathapuram, Virudhunagar, Theni and Nagerkoil centers need to get cars in the range of 30-39. (c) Vellore, Hosur, Krishnagiri, Karaikal and Erode centers need to get cars in the range of 22-29. (d) Chennai, Salem, Puducherry, Coimbatore and Tirunelveli are getting maximum no. of cars. Since, they are the major collection centers. (e) Vellore, Hosur and Krishnagiri centers are receiving less no. of cars. Table 2 shows optimal value of cars to be sent by collection centers to major repair shops. Tiruvannamalai, Ramanathapuram, Perambalur, Tiruvarur, Pudukkottai, Ariyalur and Myladuthurai centers need to send cars in the range of 33-39. Karaikal and 


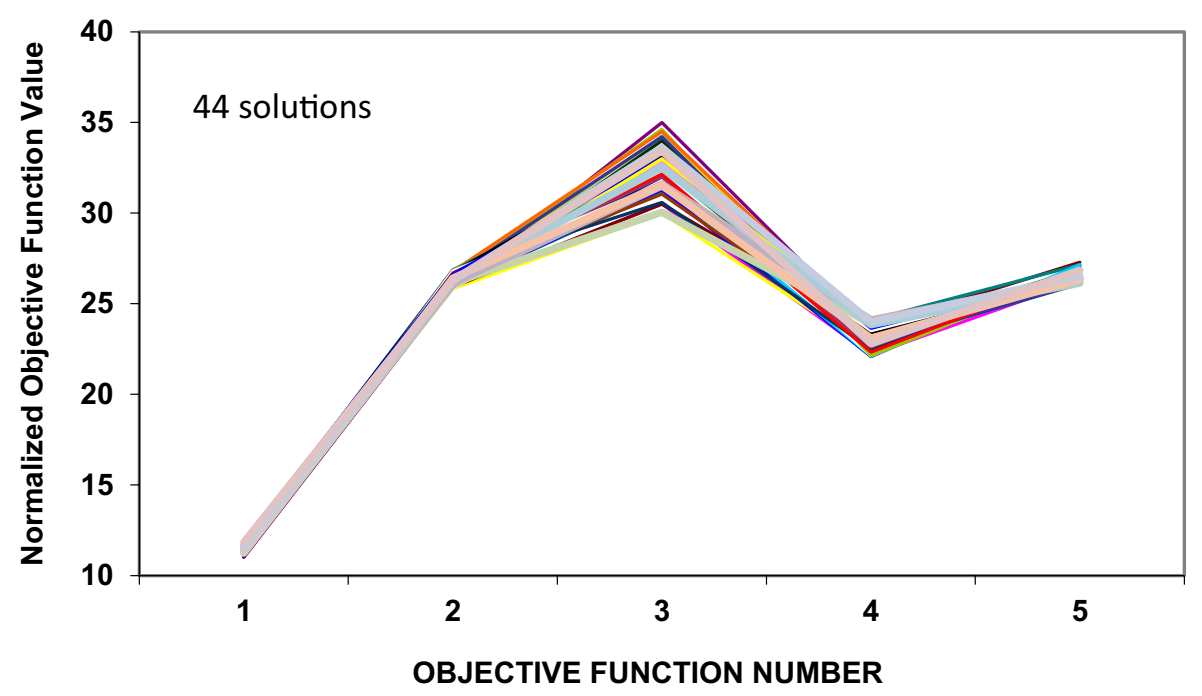

(a)

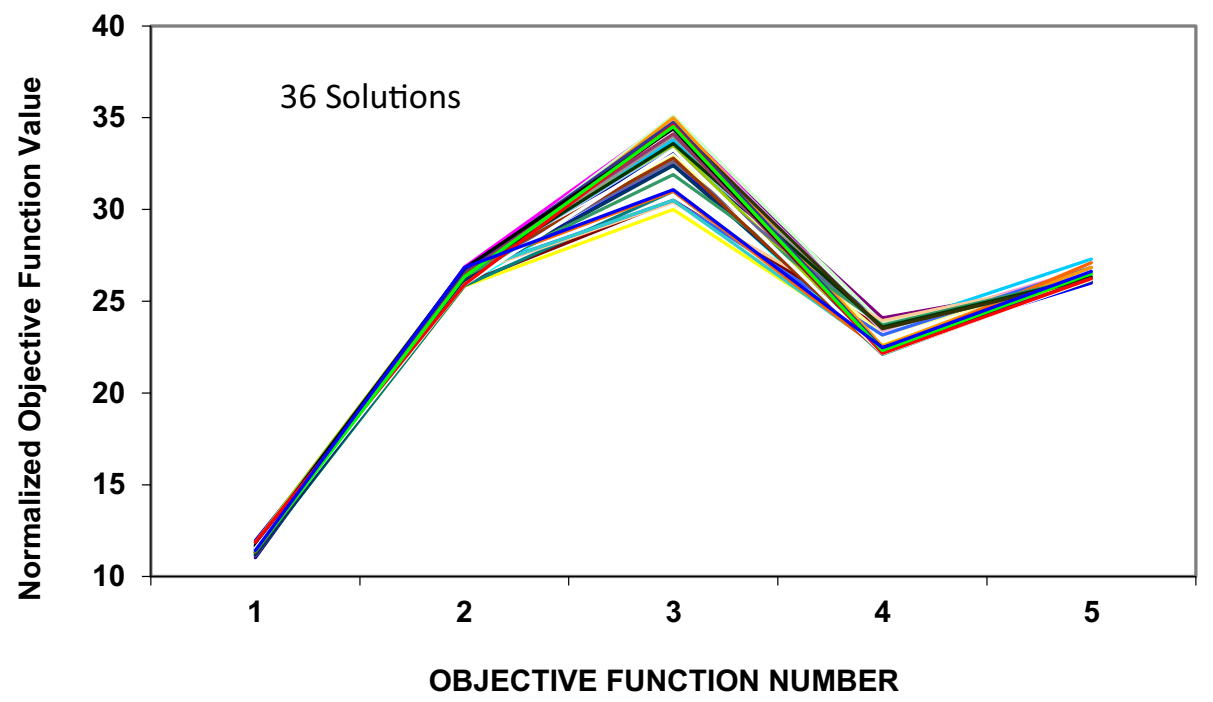

(b)

Fig.8 a Optimal trade-off solutions yielded from NSGA-II b Optimal trade-off solutions yielded from HMODE

Krishnagiri centers need to send cars in the range of 22-29. Krishnagiri center is sending less no. of cars. Since, it is the minor collection center.

Table 3 shows optimal value of cars to be repaired by major repair centers. Tanjore center is a major collection centre, and it is surrounded by more no. of centers. So, it acts as a hub. It needs to send maximum no. of cars to Trichy in the range of 191-210. Vellore and Karaikudi centers have to send cars in the range of 61-69. Dharmapuri center 
Table 1 Optimal value of number of cars to be collected by all Collection centers per year

\begin{tabular}{llllll}
\hline City name & NSGA-II & HMODE & City name & NSGA-II & HMODE \\
\hline Chennai & 45 & 44 & Tiruvarur & 39 & 38 \\
Tiruvallur & 44 & 44 & Pudukkotai & 34 & 31 \\
Kanchipuram & 32 & 32 & Ariyalur & 36 & 33 \\
Vellore & 24 & 22 & Karaikal & 29 & 22 \\
Tiruvannamalai & 37 & 36 & Myladuthurai & 34 & 30 \\
Puducherry & 46 & 45 & Coimbatore & 48 & 46 \\
Vilupuram & 41 & 40 & Erode & 29 & 27 \\
Cuddalore & 42 & 42 & Tirupur & 33 & 31 \\
Salem & 47 & 46 & Madurai & 46 & 45 \\
Hosur & 23 & 22 & Dindigul & 39 & 38 \\
Krishnagiri & 22 & 22 & Karaikudi & 36 & 35 \\
Dharmapuri & 34 & 34 & Ramanathapuram & 33 & 30 \\
Namakkal & 40 & 39 & Virudhunagar & 36 & 34 \\
Trichy & 44 & 43 & Theni & 30 & 29 \\
Karur & 33 & 32 & Tirunelveli & 47 & 46 \\
Perambalur & 37 & 36 & Tuticorin & 41 & 40 \\
Tanjore & 38 & 37 & Nagerkoil & 32 & 30 \\
\hline
\end{tabular}

Table 2 Optimal value of cars to be sent by collection centers to major repair shops

\begin{tabular}{llll}
\hline City name (From) & City name (To) & NSGA-II & HMODE \\
\hline Tiruvannamalai & Vellore & 37 & 36 \\
Ramanathapuram & Karaikudi & 33 & 30 \\
Perambalur & Trichy & 37 & 36 \\
Tiruvarur & Tanjore & 39 & 38 \\
Pudukkottai & Tanjore & 34 & 31 \\
Ariyalur & Tanjore & 36 & 33 \\
Karaikal & Tanjore & 29 & 22 \\
Myladuthurai & Tanjore & 34 & 30 \\
Krishnagiri & Dharmapuri & 22 & 22 \\
\hline
\end{tabular}

has to sends cars in the range of 56-58. Tiruvallur, Vilupuram, Cuddalore, Namakkal and Tuticorin centers have to send cars in the range of 40-44. Kanchipuram, Karur, Tirupur, Dindigul, Virudhunagar, Theni and Nagerkoil centers have to send cars in the range of 30-39. Hosur and Erode centers have to send cars in the range of 22-29. Table 4 shows optimal value of cars to be sold by resale centers per year. Trichy is a first major resale centre. It has to sell cars in the range of 266-288. Second major resale centre is Madurai. It has to sell cars in the range of 211-220. Third major resale centre is Chennai. It has to sell cars in the range of 178-182. Fourth major resale centre is Salem. It has to sell cars in the range of 164-166. Fifth major resale centre is Puducherry. It has to sell cars in the range of 127-129. Sixth major resale centers are Tirunelveli and Coimbatore. They have to sell cars in the range of 110-120.

Table 5 shows optimal values of objective functions from NSGA-II and HMODE. From Table 5, the points observed: (a) Retrieval cost, Remanufacturing cost and 
Table 3 Optimal value of cars to be repaired by major repair centers

\begin{tabular}{llll}
\hline City name (From) & City name (To) & NSGA-II & HMODE \\
\hline Vellore & Chennai & 61 & 58 \\
Tiruvallur & Chennai & 44 & 44 \\
Kanchipuram & Chennai & 32 & 32 \\
Vilupuram & Puducherry & 41 & 40 \\
Cuddalore & Puducherry & 42 & 42 \\
Namakkal & Salem & 40 & 39 \\
Dharmapuri & Salem & 56 & 56 \\
Hosur & Salem & 23 & 22 \\
Karur & Trichy & 33 & 32 \\
Tanjore & Trichy & 210 & 191 \\
Erode & Coimbatore & 29 & 27 \\
Tirupur & Coimbatore & 33 & 31 \\
Dindigul & Madurai & 39 & 38 \\
Karaikudi & Madurai & 69 & 65 \\
Virudhunagar & Madurai & 36 & 34 \\
Theni & Madurai & 30 & 29 \\
Tuticorin & Tirunelveli & 41 & 40 \\
Nagerkoil & Tirunelveli & 32 & 30 \\
\hline
\end{tabular}

Table 4 Optimal value of cars to be sold by resale centers per year

\begin{tabular}{llllllll}
\hline City no. & City name & NSGA-II & HMODE & City no & City name & NSGA-II & HMODE \\
\hline 1 & Chennai & 182 & 178 & 23 & Coimbatore & 110 & 104 \\
6 & Puducherry & 129 & 127 & 26 & Madurai & 220 & 211 \\
9 & Salem & 166 & 164 & 32 & Tirunelveli & 120 & 116 \\
14 & Trichy & 287 & 266 & & & & \\
\hline
\end{tabular}

Table 5 Optimal values of objective functions from NSGA-II and HMODE

\begin{tabular}{lll}
\hline & NSGA-II & HMODE \\
\hline f1(Retrieval cost) & $\$ 1.251 * 10^{6}$ & $\$ 1.201 * 10^{6}$ \\
f2(Transportation cost) & $\$ 3.6578^{*} 10^{4}$ & $\$ 2.7018^{*} 10^{4}$ \\
f3(Remanufacturing cost) & $\$ 1.251 * 10^{6}$ & $\$ 1.201 * 10^{6}$ \\
f4(Inventory cost) & $\$ 3.44025^{*} 10^{6}$ & $\$ 3.30275^{*} 10^{6}$ \\
f5(Rent) & $\$ 1.251 * 10^{8}$ & $\$ 1.201 * 10^{8}$ \\
f6(Labor wage) & $\$ 9.0072 * 10^{8}$ & $\$ 8.6472^{*} 10^{8}$ \\
f7(Energy cost) & $\$ 1.5012 * 10^{7}$ & $\$ 1.4412^{*} 10^{7}$ \\
F1 (Total cost) & $\$ 1.046811^{*} 10^{9}$ & $\$ 1.004964 * 10^{9}$ \\
F2(GHG Emissions) & $1.830902 * 10^{5}{ }_{\mathrm{t}} \mathrm{CO}_{2} \mathrm{e}$ & $1.352822 * 10^{5}{ }_{\mathrm{t}} \mathrm{CO}_{2} \mathrm{e}$ \\
F3(Shortage cost) & 0 & 0 \\
F(Combined objective function) & 1.0464041 & 0.842618 \\
\hline
\end{tabular}


Table 6 MOO metrics' value of MODE and NSGA-II

\begin{tabular}{lllllll}
\hline Algorithm & $T_{\text {run }}(\mathrm{sec})$ & $N_{\text {eval }}$ & AE & SSM & RNI & OO \\
\hline NSGA-II & 10 & 94 & 0.1064 & 0.0011 & 0.44 & 0.121 \\
HMODE & 10 & 115 & 0.0869 & 0.0015 & 0.36 & 0.043 \\
\hline
\end{tabular}

Rent spent by Maruti True Value (MTV) Company needs to be in the range of $\$ 1.201 * 10^{6}-\$ 1.251 * 10^{6}$. (b) Transportation cost spent by the company needs to be in the range of $\$ 2.7018^{*} 10^{4}-\$ 3.6578^{*} 10^{4}$ (c) Inventory cost spent by the company needs to be in the range of $\$ 3.30275^{*} 10^{6}-\$ 3.44025^{*} 10^{6}$. (d) Labor wages spent by the company needs to be in the range of $\$ 8.6472 * 10^{8}-\$ 9.0072 * 10^{8}$ (e) Energy cost spent by the company needs to be in the range of $\$ 1.4412 * 10^{7}-\$ 1.5012 * 10^{7}$. (f) Total cost spent by the company needs to be in the range of $\$ 1.046811 * 10^{9}-\$ 1.004964 * 10^{9}$. (g) GHG Emissions from the company needs to be in the range of $1.352822 * 10^{5}{ }_{\mathrm{t}} \mathrm{CO}_{2} \mathrm{e}-1.830902 * 10^{5} \mathrm{CO}_{2} \mathrm{e}$. There is no shortage cost. (h) To select the best optimal solution from the Pareto-optimal front, NWOF method is used. The combined objective function value of the trade-off solution yielded by HMODE is lesser than NSGA-II. So, HMODE works well. This is due to the superior ability of HMODE than NSGA-II (Sathiya and Chinnadurai 2019).

The strength or weakness of a Pareto-optimal front is evaluated by RNI and SSM. Also, $\mathrm{AE}$ and $\mathrm{OO}$ are utilized to find the computational effort of multi-objective optimization algorithms. These metrics gave best results (Sathiya and Chinnadurai 2019). Therefore, they are used in this research work. The merits of these metrics are very simple calculation, less calculation time, less memory storage and fast execution time. Table 6 gives MOO metrics' value of MODE and NSGA-II. From Table 6, the points observed: (a) No. of pure functions to be evaluated by an algorithm is less in NSGA-II. But, it is more in HMODE. (b) AE and OO values of HMODE are better than NSGA-II. So, HMODE works speeder than NSGAII. (c) RNI and SSM values of NSGA-II are better than HMODE. So, NSGA-II offered more no. of trade-off solutions with good spread of solutions along the Pareto front. (d) For this problem, both HMODE and NSGA-II are superior algorithms to be considered.

From Tables 1, 2, 3, 4, 5, 6, it is noted that HMODE techniques gave better results than NSGA-II. So, in overall view, HMODE technique is superior to NSGA-II. By using the proposed optimization model, all the costs associated with the design of RSC network for collecting used cars by Maruti True Value Company such as Retrieval cost, Transportation cost, Remanufacturing cost, Inventory cost Rent cost, Labor cost, Energy cost and shortage cost are minimized. GHG emissions are also minimized. Also, all the necessary constraints are satisfied. Total GHG emissions are well within the Carbon strict cap (CSC). The proposed optimization model can be used to find GHG emissions from collection centers, repair shops, resale shops and car carrier trucks. By analyzing GHG emissions from all sources, an environmental and economics research can be done.

\section{Conclusions and recommendations}

The RSC is a major solution to get environment friendly goods and to increase the end-oflife products (Piyawat Chanintrakul et al. 2009). It gives benefits related to the environment and economic and also influences costs, emissions during transportation, collection, recovery facilities, recycling, disassembly, remanufacturing and removal of reusable components (Alkhayyal and Gupta 2018). Sustainable supply chain is the art of managing materials, 
information, capital flows and cooperation among industries. It guides to sustainable development in environmental and socio-economic requirements of company people and customer requirements. In this research work, supply chain finance is considered to maximize the profits and to minimize costs, $\mathrm{CO}_{2}$ emissions, transportation, energy use, rent, product recovery costs and labor. By diminishing GHG emissions as per government regulations, the environmental damages are reduced. This guides to environmental sustainability. This environmental sustainability reduces the negative components like disease, traffic congestion, noise, stress and coastal destruction. It also leads to upgrading quality of life.

This research work presented two strategies for reducing costs and GHG emissions in a RSC network. In the first strategy, a solar-powered AGV is suggested for Maruti True Value RSC management. AGVs are increasing sustainability and efficiency of both FSCs and RSCs (Bechtsis et al. 2017a). They very much reduce transportation problems. They are very helpful in making decision across strategic, operational and tactical levels of SCs. AGVs cost is a conflicting factor. But they have high flexibility and more adaptability. So, they can reduce internal problems of SCs and increase quickness in all industries (Guilherme T Aguiara et al. (2019). In this digitalization era, AGVs help very much to SCs to overcome consequences of classical reverse supply networks. They offer good assistance to sustainable RSCs in design, planning and also in management. From the proposed strategy 1, the concluded points are: (1) For total elimination of GHG emissions during transportation, the usage of AGV is a predominant solution. (2) This strategy gives an insight into diminishing GHG emissions by using a solar powered AGV system. (3) The design details of physical components, controller system, wireless communication system, navigation system and server controller system design and path planning method of AGV have been discussed.

In the second strategy, by considering both operational and strategic parameters which influences the environment, a RSC optimization model designed and tested in a real industrial situation. The concluded points are: (1) The proposed model reduces the costs and GHG emissions. (2) Both NSGA-II and HMODE techniques work well for this problem. But HMODE gives better results than NSGA-II due to its superior nature. (3) Transport operations in a RSC are the major cause for GHG emissions. (4) Optimization of transportation activities gives a solution to this problem. Optimal transportation movements reduce GHG emissions for a major amount. (5) The Carbon strict cap constraint reduces amount of carbon emissions from supply chain operations. (6) So the proposed strategy reduces the carbon footprints in a RSC network.

The recommendations from this research work are (1) AGVs are a good alternate solution to transportation problems of RSC. So, they can be used instead of conventional carcarrier trucks. (2) Solar powered AGVs are better than conventional AGVs. (3) The proposed HMODE and NSGA-II can be used for optimizing all activities of RSCs. They can be considered as alternative solutions for existing methods in RSC management system.

\subsection{Limitations and future scope}

More assumptions have been made in developing the optimization model. So the developed optimization model can be improved by reducing assumptions and including more practical constraints. Practical constraints related to Delay factors like traffic jam in the road, climate conditions (like rain, storm, snow and desert), maintenance of transport vehicles, human workers' problems can be included in the optimization model. Another future work is constructing and testing of solar powered AGV for a RSC network. 


\section{Managerial implication}

This research works investigated on how to change RSC of a used-cars resale company as an environment friendly and sustainable nature. The methods suggested are helpful to the company to increase their efficiency and societal concerns. The outcome from this research work helps the company to move forward in making technological advancement and carbon foot-prints reduction. Technological change is a vital one to move forward toward green RSC. Initial cost to procure AGV is high. But, AGV manufactures will reduce the cost if they go for mass production. So to implement green RSC, the company needs to design and fabricate its own AGVs. Otherwise, the company can purchase AGVs. Cost requirement can be the barrier for implementation of green RSC for any company. But, they must break that barrier in order to ensure continuance of the company. Further, solar powered AGVs are reducing transportation cost and time. Solar power usage in any company has to be increased. Since, any industry cannot only rely on fossil fuel sources for long term. It is the right time all industries are keen to increase the usage of solar power. Also, they have to advance their goods carrying medium by AGVs. They have to reduce the usage of conventional car-carriers which are running by diesel. This is the first research work to analyze RSC of a used-cars resale company (Maruti True value). The investigation of this research leads to adaption of green and sustainable RSC in Maruti True Value Company.

\section{Appendix}

Survey Form about Maruti True Value Center

General details

Employee Name:

Company/Showroom Name:

Address:

Questionnaire (Give details in brief)

1. Works undertaken (Put a tick mark):

Used car Collection- Major/Minor, Repair- Major/Minor, Resale- Major/Minor.

2. Rent of the centre/year (in Rs):

3. Number of labors and their total salary details:

4. Energy conservation details (Electricity bills)—energy cost/year:

5. Transportation facilities available:

a. Car carrier truck details:

b. Transportation cost/truck(in Rs):

6. GHG emissions from this center/year:

7. GHG emissions from a car carrying truck $/ \mathrm{km}$ :

8. Nearby used car collection centre:

9. Nearby used car Major Repair workshop:

10. Nearby used car Major resale centre:

11. Carbon Strict Cap (CSC) allowable:

12. Allowed GHG emissions stated by Government agencies: 
Used cars' collection details

13. Car models:

14. Maximum weight of a car (in $\mathrm{kg}$ ):

15. Customers' opinions about car resale requirements:

16. Average Retrieval cost/car (in Rs):

17. Maximum capacity to collect used cars:

18. Space available for collection of used cars (in sq.m):

Used cars' repair works details

19. Major problems associated with Maruti Suzuki cars:

20. Facilities available for doing repair works:

21. Maximum capacity to repair cars:

22. Total space for repairing cars (in sq.m):

Used cars' resale details

23. Demand of resale cars:

24. Resale capacity:

25. Total space for resale of cars (in sq.m):

26. Total resale cost:

27. Shortage cost per car:

28. Any other details willing to share:

Employee Signature.

\section{References}

Abdallah, T., Farhat, A., Diabat, A., \& Kennedy, S. (2012). Green supply chains with carbon trading and environmental sourcing: Formulation and life cycle assessment. Applied Mathematical Modelling, 36(9), 4271-4285.

Afshari, H., Sharafi, M., ElMekkawy, T. Y., \& Peng, Q. (2016). Multi-objective optimisation of facility location decisions within integrated forward/reverse logistics under uncertainty. International Journal of Business Performance and Supply Chain Modelling, 8(3), 250-276.

Aguiara, G. T., Oliveiraa, G. A., Tanb, K. H., Kazantsevc, N., \& Setti, D. (2019). Sustainable implementation success factors of AGVs in the Brazilian industry supply chain management. Procedia Manufacturing, 39, 1577-1586.

Alkhayyal, A. (2019a). Designing an optimization carbon cost network in a reverse supply chain. Production and Manufacturing Research, 7(1), 271-293.

Alkhayyal, B. (2019b). Corporate social responsibility practices in the U.S.: Using reverse supply chain network design and optimization considering carbon cost. Sustainability, 11(7), 2097.

Alkhayyal, B. A., \& Gupta, S. M. (2018). The impact of carbon emissions policies on reverse supply chain network design. DoğuşÜniversitesiDergisi, 19(1), 99-111.

Alzaman, C. (2016). Impact of optimisation on idle time's fuel consumption and $\mathrm{CO}_{2}$ emissions in urban transportation. International Journal of Business Performance and Supply Chain Modelling, 8(2), $157-179$.

Azevedo, S. G., Carvalho, H., Ferreira, L. M., \& Matias, J. C. O. (2017). A proposed framework to assess upstream supply chain sustainability. Environment, Development and Sustainability, 19, 2253-2273.

Bechtsis, D., Tsolakis, N., Vlachos, D., \& Iakovou, E. (2017a). Sustainable supply chain management in the digitalisation era: The impact of automated guided vehicles. Journal of Cleaner Production, 142, 3970-3984.

Benjaafar, S., Li, Y., \& Daskin, M. (2013). Carbon footprint and the management of supply chains: Insights from simple models. IEEE Transactions Automotive Science Engineering, 10, 99-116.

Blackburn, J. D., Daniel, V., Guide, R., Jr., Souza, G. C., \& Van Wassenhove, L. N. (2004). Reverse supply chains for commercial returns. California Management Review, 46(2), 5-22. 
Bostelman, R., Teizer, J., Ray, S. J., Agronin, M., \& Albanese, D. (2014). Methods for improving visibility measurement standards of powered industrial vehicles. Safety Science, 62, 257-270.

Chanintrakul, P., Coronado Mondragon, A. E., Lalwani, C., \& Wong, C. Y. (2009). Reverse logistics network design: A state-of-the-art literature review. International Journal of Business Performance and Supply Chain Modelling, 1(1), 61-81.

Chaudhary, K., \& Vrat, P. (2020). Circular economy model of gold recovery from cell phones using system dynamics approach: A case study of India. Environment, Development and Sustainability, 22, $173-200$.

Choe, R., Kim, J., \& Ryu, K. R. (2016). Online preference learning for adaptive dispatching of AGVs in an automated container terminal. Applied Software Computing Journal, 38, 647-660.

D'Andrea, R. (2012). Guest editorial-A revolution in the warehouse: A retrospective on kiva systems and the grand challenges ahead. IEEE Transactions on Automation Science and Engineering, 9(4), 638-639.

Deb, K., Pratap, A., Agarwal, S., \& Meyarivan, T. (2002). A fast and elitist multiobjective genetic algorithm: NSGA-II. IEEE transactions on Evolutionary computation, 6(2), 182-197.

Diabat, A., Abdallah, T., Al-Refaie, A., Svetinovic, D., \& Govindan, K. (2013a). Strategic closed-loop facility location problem with carbon market trading. IEEE Transactions on engineering Management, 60(2), 398-408.

Diabat, A., Kannan, D., Kaliyan, M., \& Svetinovic, D. (2013b). An optimization model for product returns using genetic algorithms and artificial immune system. Resources, Conservation and Recycling, 74, 156-169.

Diabat, A. \& Simichi-Levi, D. (2010). A carbon-capped supply chain network problem, IEEE international conference on industrial engineering and engineering management, 523-527.

Fahimnia, B., Sarkis, J., Dehghanian, F., Banihashemi, N., \& Rahmanm, S. (2013). The impact of carbon pricing on a closed-loop supply chain: An Australian case study. Journal of Cleaner Production, $59,210-225$.

Fazlollahtabar, H., Saidi-Mehrabad, M., \& Balakrishnan, J. (2015). Mathematical optimization for earliness/tardiness minimization in a multiple automated guided vehicle manufacturing system via integrated heuristic algorithms. Robotics and Autonomous Systems, 72, 131-138.

Gelareh, S., Marzouki, R., McGinley, M., \& Murray, R. (2013). Scheduling of intelligent and autonomous vehicles under pairing/unpairing collaboration strategy in container terminals. Transportation Research Part C: Emerging Technologies, 33, 1-21.

Giret, A., Trentesaux, D., \& Prabhu, V. (2015). Sustainability in manufacturing operations scheduling: A state of the art review. Journal of Manufacturing Systems, 37, 126-140.

Ilgin, M. A., \& Gupta, S. M. (2010). Environmentally conscious manufacturing and product recovery (ECMPRO): A review of the state of the art. Journal of environmental management, 91(3), 563-591.

Jaegler, A., \& Gondran, N. (2014). Estimating the carbon footprint of a road freight firm, perspectives to mitigate these emissions. International Journal of Business Performance and Supply Chain Modelling, 6(3/4), 239-254.

Jin, M., Granda-Marulanda, N. A., \& Ian, D. (2014). The impact of carbon policies on supply chain design and logistics of a major retailer. Journal of Cleaner Production, 85, 453-461.

Kalakou, S., Psaraki-Kalouptsidi, V., \& Moura, F. (2015). Future airport terminals: New technologies promise capacity gains. Journal of Air Transport Management, 42, 203-212.

Kannan, D., Diabat, A., Alrefaei, M., Govindan, K., \& Yong, G. (2012). A carbon footprint based reverse logistics network design model. Resources, Conservation and Recycling, 67, 75-79.

Kumar, A., \& Rahman, S. (2014). RFID-enabled process reengineering of closed-loop supply chains in the healthcare industry of Singapore. Journal of Cleaner Production, 85, 382-394.

Material Handling Industry (MHI) Annual Industry Report 2016, Accelerating change: How innovation is driving digital, always-on supply chains. Retrieved March 30, 2020, from https://cpbucket.fiu. edu/1168-geb6368x81168_emba-97075\%2F2016-industry-report-2016-(1).pdf.

NageswaraReddya, K., Kumara, A., Sarkisb, J., \& Tiwaria, M. K. (2020). Effect of carbon tax on reverse logistics network design. Computers and Industrial Engineering, 139, 106184.

Paksoy, T., Bektaş, T., \& Özceylan, E. (2011). Operational and environmental performance measures in a multi-product closed-loop supply chain. Transportation Research Part E: Logistics and Transportation Review, 47(4), 532-546.

Qin, A. K., Huang, V. L., \& Suganthan, P. N. (2009). Differential evolution algorithm with strategy adaptation for global numerical optimization. IEEE Transactions on Evolutionary Computation, $13(2), 398-417$. 
Sabattini L., Digani V., Secchi C., Cotena G., Ronzoni D., Foppoli M. \& Oleari F. (2013). ‘Technological roadmap to boost the introduction of AGVs in industrial applications, Proceedings-2013 IEEE 9th international conference on intelligent computer communication and processing, ICCP 2013 6646109, 203-208.

Sathiya, V., \& Chinnadurai, M. (2019). Evolutionary algorithms-based multi-objective optimal mobile robot trajectory planning. Robotica, 37(8), 1363-1382.

Schmidt, J., Meyer-Barlag, C., Eisel, M., Kolbe, L. M., \& Appelrath, H. J. (2015). Using battery-electric AGVs in container terminals-Assessing the potential and optimizing the economic viability. Research in Transportation Business and Management, 17, 99-111.

Sheu, J. (2008). Green supply chain management, reverse logistics and nuclear power generation. Transportation Research Part E: Logistics and Transportation Review, 44, 19-46.

Shukla, A., \& Karki, H. (2016). Application of robotics in offshore oil and gas industry-A review Part II. Robotics and Autonomous Systems, 75, 508-524.

Waltho, C., Elhedhli, S., \& Gzara, F. (2019). Green supply chain network design: A review focused on policy adoption and emission quantification. International Journal of Production Economics, 208, 305-318.

Zhang, J., \& Sanderson, A. C. (2009). JADE: Adaptive differential evolution with optional external archive. IEEE Transactions on Evolutionary Computation, 13(5), 945-958.

Publisher's Note Springer Nature remains neutral with regard to jurisdictional claims in published maps and institutional affiliations.

\section{Affiliations}

\section{Sathiya ${ }^{1} \cdot$ M. Chinnadurai ${ }^{2} \cdot$ S. Ramabalan ${ }^{3} \cdot$ Andrea Appolloni $^{4}$}

M. Chinnadurai

mchinna81@gmail.com

S. Ramabalan

cadsrb@gmail.com

Andrea Appolloni

andrea.appolloni@uniroma2.it

1 Department of Electronics and Communication Engineering, E.G.S. Pillay Engineering College,

Nagapattinam, Tamil Nadu 611002, India

2 Department of Computer Science and Engineering, E.G.S. Pillay Engineering College, Nagapattinam, Tamil Nadu 611002, India

3 Department of Mechanical Engineering, E.G.S. Pillay Engineering College, Nagapattinam, Tamil Nadu 611002, India

4 Department of Management and Law, University of Rome Tor Vergata, Via Columbia, 2, 00133 Rome, Italy 